\title{
Antidepressant advertising in China and the UK: the strength and limits of policy learning
}

Robert Geyer ${ }^{1}$,

Fang Wang ${ }^{2}$ (Corresponding author)

\begin{abstract}
China is expected to become one of the largest markets for prescription drugs in the world and pharmaceutical advertising is becoming increasingly important, particularly in the highly socially and culturally contested area of mental health. This article briefly explores the background of drug advertising policies in China and the UK and focuses on the distinctive challenges of antidepressant drug regulation. Then, using tools of Critical Discourse Analysis, it examines Chinese antidepressants adverts, and compares them with relevant British adverts. The findings indicate that, relative to the UK, Chinese antidepressant adverts are generally oversimplified, and the critical information concerning the concepts of caution, danger and adverse effects are underrepresented. However, there are many interdependent factors that contribute to the distinctive Chinese antidepressant drug regulatory regime. Hence, Chinese policy makers must maintain a delicate balance between learning from Western regulatory regimes, but also avoiding borrowing too heavily from them.
\end{abstract}

Key words: antidepressant advertising, China, Critical Discourse Analysis, prescription drug regulation, policy learning

随着中国正在逐渐成为世界上最大的处方药物市场, 药物广告, 尤其是精 神类药物广告由于其复杂的社会与文化属性而经常成为一个充满争议的热点话 题。本文首先阐述了中英两国广告政策的异同, 并着重分析了在抗抑郁症药物 广告领域中国目前面临的挑战。然后, 运用批评话语分析的研究方法, 本研究 详细比较了中英两国抗抑郁症药物广告的话语特点, 并发现相比较于英国而言, 中国目前的抗抑郁症药物广告存在整体文本过于简单化，对药物的不良反应， 风险性及注意事项等方面表述不足的问题。这一现象和中国特有的抗抑郁症药 物管理体系及其他因素息息相关。因此相关领域政策制定者需要在借鉴他国经 验和保持本国管理体系特色两者之间寻求一种合理的平衡状态。

\section{Introduction}

\footnotetext{
${ }^{1}$ Department of Politics, Philosophy and Religion, Lancaster University (r.geyer@lancaster.ac.uk)

${ }^{2}$ Centre for Translation Studies, University of Surrey (fang.wang@surrey.ac.uk)
} 
With the growing array of mediations and their availability on the internet, drug advertising and its regulation is becoming increasingly important to individuals and societies and is widely discussed in the fields of discourse analysis ${ }^{3}$, policy studies ${ }^{4}$ and social research ${ }^{5}$. Drug advertising blends health, scientific and commercial information, and the representation of drug advertising is largely shaped by a wide range of factors from the institutional and social levels. Drug advertising is also a major economic activity. Global pharmaceutical companies spend between 24 per cent and 33 per cent of total sales revenue on marketing, advertising and promotional activities, about twice as much as on research and development ${ }^{6}$. They are also important political actors on the local, national and international levels.

The Chinese case is particularly interesting and important since the Chinese health system has recently gone through a number of huge transformations since the 1980s. Moreover, the changing and contested role of drugs and drug advertising (particularly in relation to mental health) in China makes it potentially one of the largest and most contested markets for prescription drugs (and antidepressants) in the world. At present, direct-to-consumer-advertising for prescription drugs (DTCA-PD) is illegal in China. However, with the growth of globalization and the internet, access to drug advertising is becoming increasingly difficult to control.

In this article, the focus is on the Chinese case. However, in order to understand its relative distinctiveness we will be comparing it to the UK case. The UK was chosen because it has a key similarity to the Chinese context - in both cases prescription drug advertising is illegal except in recognized medical journals (hence ruling out a ChinaUSA comparison). It also has an important difference - the UK has a relatively lengthy history of both antidepressant usage and advertising regulation whereas China has limited experience of both. Using tools from critical discourse analysis to explore the

\footnotetext{
${ }^{3}$ Glinert 2005; Jones, Greenfield and Bradley 1999.

${ }^{4}$ Geyer 2011; Stryer and Bero 1996; Lee et al. 1991.

${ }^{5}$ Cohen et al. 2001; Lövdahl, Riska and Riska 1999.

${ }^{6}$ House of Commons 2005.
} 
linguistic and discursive patterns of antidepressant advertisements in Chinese and UK medical journals, we will examine how linguistic patterns in anti-depressant drug advertising in China and the UK have evolved in recent times and explore some of the wider policy contexts that have shaped these developments. The research concludes by exploring: what elements are central in the development of the drug advertising policies in China and what are the key implications for both academics and policy actors in understanding governance and policy making in this area?

\section{Theoretical framework}

Though grounded in Complexity Theory ${ }^{7}$ and its overlapping relationship with Critical Discourse Analysis ${ }^{8}$, the theoretical framework of this article is located in Critical Discourse Analysis (CDA) and its implications for policy learning and transfer. CDA aims "to show how semiotic, including linguistic, properties of the text connect with what is going on socially in the interaction"9. What is essential for CDA, then, is to analyze structures of language use, and to systematically relate them to structures of the sociocultural context of language use. From this sense, CDA goes beyond linguistic analysis, and "seeks to locate discourse within a social world of conflict and inequality" ${ }^{\prime 10}$, looking at common concerns shared by social theory and sociolinguistics and contributing to explain the interaction between social structures and language use.

CDA has been recently applied to policy studies in the areas of educational policy ${ }^{11}$, public housing policy ${ }^{12}$, urban policy research ${ }^{13}$, adult literacy policy ${ }^{14}$ and a range of other areas. CDA is distinct from other approaches in policy studies in the standing

7 Core works of complexity theory and policy include: Byrne and Callaghan 2013; Coveney and Highfield 1995; Geyer and Rihani 2010; Geyer and Cairney 2015; Mainzer 1997.

8 Key works on the relationship between complexity and critical discourse analysis include: Cameron and LarsenFreeman 2007; Larsen-Freeman 1997, Larsen-Freeman and Cameron 2008.

9 Fairclough 2001, 240.

10 Sealey and Carter, 2004, 58.

11 Falk 1994; Luke 1997.

12 Marston 2000.

13 Jacob 2006.

14 Hamilton 2014. 
which it gives to language analysis - analysis of 'texts' in a comprehensive sense within discourse analysis. As Fairclough argues, in policy-making and policy debate, there is a focal relationship between problem and solution; CDA, although does not aim to find such solutions, can contribute to developing models for analysing them that accentuate this relationship." ${ }^{\prime 15}$ Hence, the work of this article is to explore the features of language-using in Chinese antidepressant advertisements and connect them with the multiple levels of discursive events and policy-related socioeconomic contexts that give rise to such language use.

Given the inherent complexity and subtlety of multi-level, political-linguistic policy making, we intend to question traditional implications of policy learning and transfer. There is a very lengthy history within different fields of policy studies regarding the importance and implications of policy learning and transfer between different countries and policy contexts. For example, post WW2 modernization theory promoted the simplistic belief that fundamentally all developing countries had to do in order to develop was to copy, as closely as possible, the policy strategies of developed nations and they would automatically develop. This was followed in the 1970s and 1980s by the emphasis of the World Bank/IMF on a common 'structural adjustment framework' for all developing countries. ${ }^{16}$ Again, the implication was that Western policies were more advance and that imitating their policy structures and strategies was the quickest road to success. More subtle concepts of 'policy learning and transfer' and 'governance' instead of 'government' emerged in the 1990s and 2000s which recognized the highly contextual nature of policy making and limits of direct policy learning and transfer. ${ }^{17}$ However, they were countered by the narratives of 'new public management' and 'evidence based policy making' which often reasserted the dominance of traditional forms of Western policy-making. ${ }^{18}$

15 Fairclough 2013, 183.

16 Easterly 2006, George 1994; Rihani 2002.

17 Dolowitz and Marsh 2000; Benson and Jordan 2011.

18 Ansell and Geyer 2017; Cairney 2015; Geyer 2012. 
In this article, we do not have the space to explore these debates in detail. Nevertheless, our comparative discourse analysis of the Chinese and UK policies shines a distinctive light on the importance of policy learning/transfer and at the same time, the inherent limits and difficulties of such learning and the need to continually critically evaluate and assess it.

\section{A brief background of prescription drug advertising regulations in the UK}

In the UK, the control of medicines advertising was originally based on self-regulation ${ }^{19}$. However, direct to consumer advertising for prescription drugs (DTCA-PD) was very limited and made illegal by the March 1992 EU Directive on the advertising of medical products for human use (Directive 92/28/EEC) which prohibited DTCA-PD within the European Union. ${ }^{20}$ As early as 1958 , guidance for advertising to medical practitioners was provided by the Association of British Pharmaceutical Industry (ABPI). In 1974 the ABPI begun to provide the guidelines that resulted in the current form of prescription drugs adverts and the most updated version was published in 2016 (ABPI, 2016). These guidelines largely conform with the requirements of prescription drugs adverts to medical practitioners recommended by the Ethical Criteria for Medicinal Drug Promotion developed by the World Health Organisation (WHO, 1988), both indicate that information related to names of medicine (both generic and brand), active ingredients, dosage, side-effects, precautions, major interactions, etc. In addition, a separate body, the Prescription Medicines Code of Practice Authority (PMCPA) ${ }^{21}$, operates a Code of Practice for the pharmaceutical industry independently of the ABPI.

Hence, the UK has had a highly regulated environment for prescription drug advertising to medical practitioners for over 30 years and conforms with WHO standards. This is confirmed in a study by Lexchin ${ }^{22}(2010)$ who notes that although medical journals

\footnotetext{
${ }^{19}$ Green, Haddad and Aronson 2018, 1670.

${ }^{20}$ Geyer 2011

${ }^{21}$ PMCPA 2018.

22 Lexchin 2010.
} 
from developed countries contain the information suggested by the ethical criteria developed by the WHO (1988), the safety information is systematically ignored in developing countries. As we will explore, less developed regulatory systems and sociocultural issues surrounding mental health conditions may play an important role in shaping the current forms of antidepressant adverts to medical practitioners.

\section{The Sociocultural context of mental depression and the transformation of anti-depressant drug advertising policy in China}

\subsection{Sociocultural context of mental depression and the rise of marketisation of antidepressants in China}

In China, one central concept of Chinese culture and medicine appears to be the天人相 应 (tian ren xiang ying, 'correspondence between microcosm and macrocosm') ${ }^{23}$. This means that health is maintained when there is a balanced and harmonious relationship between the human body and the environment. Mental depression can be traced back to the concept of 郁症 ( $y u$ zheng, 'stagnation syndrome') in traditional Chinese medicine, which explains it as an imbalance of different elements in the human body ${ }^{24}$. The treatment of such a condition, therefore, often relies on the improvement of the social environment or the balance of different elements in the human body. Kleinman ${ }^{25}$ pointed out the overwhelmingly social foundations of mental illnesses in Chinese society and, in his later work, argued that "attributions of illness onset to social sources, the symbolic linking of symptoms to life context, and the alleviation of distress with improvement in circumstances point to the sociosomatic mediation of sickness"26.

Therefore, the use of antidepressants has been marginalised in Chinese society for much of the $20^{\text {th }}$ century and there is still strong resistance to biomedical treatments for mental

\footnotetext{
${ }^{23} \operatorname{Lin} 1980,96$.

${ }^{24} \mathrm{Ng}$, Chan, Ho, Wong and Ho 2006.

25 Kleinman 1982.

${ }^{26}$ Kleinman1992, 546.
} 
and emotional disorders. Baum ${ }^{27}$ examined the tension between legislative change (at the level of the state) and phenomenological consistency (at the level of the society and individual) surrounding mental health problems in early 1920s in China, and concluded that to many contemporary Chinese minds, the theoretical underpinnings of biomedicine and scientific psychiatry were inscrutably foreign, improbable, and useless in their approach to psychobiological disorder ${ }^{28}$. A relevant point here is that the sideeffects of biomedicines have not been generally acceptable for Chinese people, who had long-established tradition of using natural herbal medicine. As we will argue later, this may be connected with the omission of information related to adverse effects in Chinese antidepressant adverts.

However, a significant change in the Chinese discussion of depression and the use of antidepressants has taken place in the last ten years. Wang ${ }^{29}$ conducted a longitudinal study examining the discussions about mental depression in British and Chinese newspapers in the last three decades, finding that Chinese people still frame the discussion of mental depression with traditional Chinese concepts, but the depiction of depression as a chemical condition started to appear in a significant number of Chinese articles since $2009^{30}$. At the same time, rising health care needs combined with pharmaceutical industry development has led to a large-scale market expansion of antidepressants. Sales of antidepressants have risen from 25.1 to 56.74 billion RMB in the last five years, and are estimated to exceed 60 billion RMB in $2017^{31}$. This mixture has led to a re-conceptualisation that differs in important ways from the Western concept. Therefore, it is important to look into the ways in which antidepressants were advertised and how the language reflected the sociocultural context.

The next section briefly discusses the policy-related socioeconomic contexts of

\footnotetext{
27 Baum 2013.

28 Ibid 4.

${ }^{29}$ Wang 2013.

${ }^{30}$ Ibid 280

${ }^{31}$ Jin 2016.
} 
antidepressants advertising, including the upheaval of Chinese healthcare system and China's prescription drug advertising regulatory background, its current status and challenges. This will not only contribute to unravelling the interaction between language use in antidepressant adverts and the related policy practices, but will provide more insight into comparative policy learning and transfer.

\subsection{The background of drug advertising policies in China}

In the past 30 years China has gone through huge changes in its health policy and systems. During the 1960s and 70s, China's health system was prevention oriented, public health based, and people-centered using local 'barefoot doctors'. At that time, it was praised by the World Health Organization for its successful vaccination programmes, elimination of malaria, improving mortality rates for under 5's, elimination of opium usage, and a range of other basic health achievements. Key changes occurred following the transition to a more market-oriented approach to development in the early to mid-1990s. Under the new system, state funded health care was replaced with care funded by a mix of local government, employer and individual contributions and private provision of health care was promoted. At the time of huge economic upheaval this led to a range of problems including: huge regional variation and growing inequality of access to care, growing business orientation and loss of public health-oriented culture of the profession ${ }^{32}$, and poor regulation and corruption. By the mid-2000s, the WHO, World Bank and even the Economist criticized China for pushing the health market too far/fast ${ }^{33}$. In response, in 2007 President Hu Jintao announced a major health reform to increase funding, make the system more patientcentered and strengthen its public orientation. However, problems persist in relation to growing costs, huge variation in outcomes and access and hidden corruption.

In relation to prescription drug advertising, early regulation from 1978-1993 made no distinction between prescription and non-prescription drugs. However, from 1994

\footnotetext{
32 Zhan 2011.

33 lbid.
} 
onwards the state authorities defined advertising and separated prescription and nonprescription drugs. The main regulations concerning the pharmaceutical advertising in China are the Advertising Law (promulgated in 1995 and amended in 2015), the Law for the Administration of Pharmaceuticals (adopted in 2002), the Standards for the Examination and Publication of Drug Advertisements (effective from May 1, 2007 and is now under revision), and the Measures for the Examination of Drug Advertisements (effective from May 1, 2007). The latest Advertisement Law of the People's Republic of China (2015), amended and revised by the Standing Committee of the National People's Congress (NPC) and State Administration for Industry \& Commerce (SAIC) ${ }^{34}$, strengthened the inclusion of the critical information about drugs and reaffirmed the ban on prescription drug advertising (except in professional journals):

- Article 16: Drug and device advertisements must clearly state critical information about the products, such as contraindication and adverse effects; Drug and device advertisements must not contain absolute assurances or guarantees of the product's safety.

- Article 19: Mass media (including broadcasting, television and the internet) cannot feature drug, device, health supplement and medical service advertisements in disguised forms, such as in news reports or health-related public education programs, so as to circumvent being regulated as advertisements.

\subsection{China's prescription drug advertising regulatory challenges}

Ma and Lou ${ }^{35}$ pointed out that although the Chinese government oversees prescription drug advertisements and relies on strict pre-approval requirements, compared to the huge sums spent on drug promotion, government resources are limited to regulate and enforce. $\mathrm{Bai}^{36}$ notes that approval authorities of prescription drug advertising in China

\footnotetext{
${ }^{34}$ Standing Committee of the NPC and SAIC 2015.

${ }^{35} \mathrm{Ma}$ and Lou 2014.

${ }^{36}$ Bai 2015.
} 
are only regularly trained to understand relevant policies and regulations and to improve their implementation competence, without being provided sufficient, efficient and reliable drug information. Thirdly, China now operates an Essential Drugs List (EDL), a list of core medicines that are reimbursable under Basic Medical Insurance at the national and provincial level. The importance of the EDL weakens the role of drug advertising strategies for those drugs on the list since manufacturers can be guaranteed a significant market share ${ }^{37}$. However, it also pushes those producers who are not on the list to use unbalanced and untruthful advertising to increase market share.

\section{A Critical Discourse Analysis of antidepressant advertisements in China}

Chinese drug advertising polices state that prescription drugs are only allowed to be advertised in officially-approved medical journals. This research looks at all the antidepressant advertisements published in China's leading journal in relation to psychiatric illness: The Chinese Journal of Psychiatry - from 1996, when the journal was founded, to 2015. This journal was a quarterly publication from 1996 to 2011, and became a bi-monthly from 2012. The following chart shows the total number of advertisements in each year of the journal:

Table 1: The number of antidepressant advertisements in The Chinese Journal of Psychiatry from 1996 to 2015

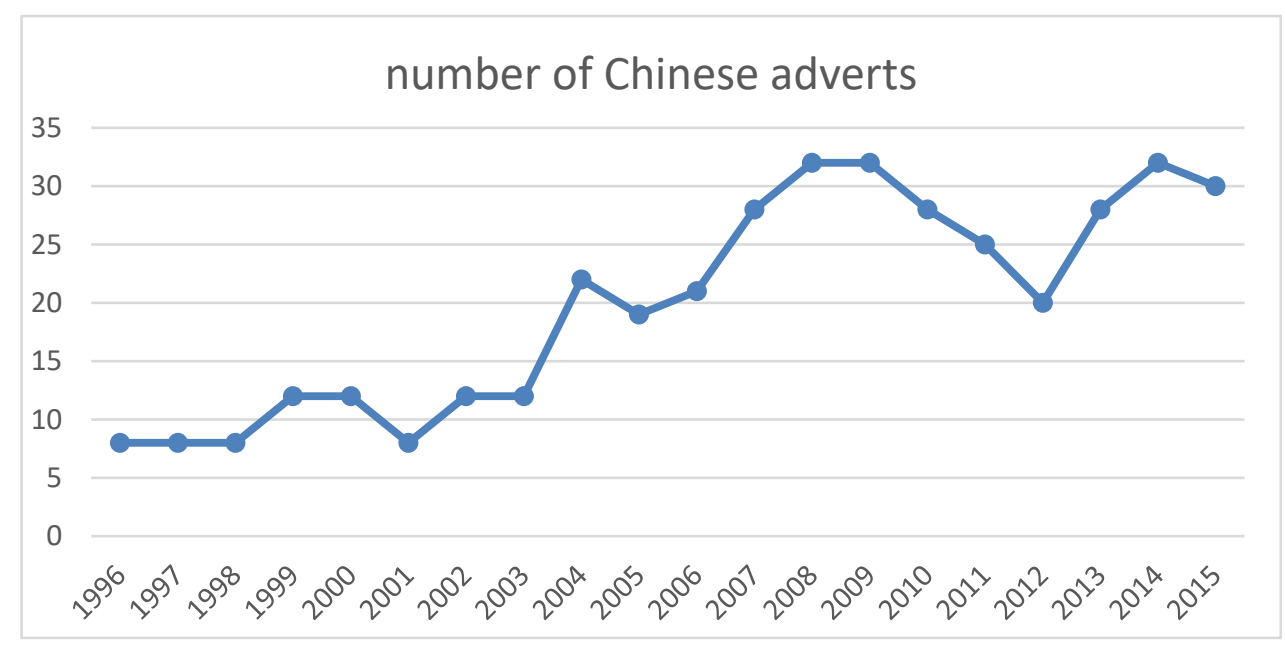

${ }^{37}$ Shi and Ling 2007. 
As this table shows, the number of advertisements in this medical journal has increased significantly over the last 20 years. From 1996 to 2003, the number rose steadily, despite a slight fall in 2001. 2004 saw rapid growth with the total number of advertisements almost doubled from 2003. This is because in 2003, the Chinese government started to increase investment in the public health system due to the SARS crisis. As a result, the prescription drugs market began to be more active. 2005 saw a slight decrease in the frequency of the advertisements, but subsequently the number of advertisements kept increasing until 2008, when the frequency spiked. The dip between 2012 and 2014 is related primarily to editorial changes in The Chinese Journal of Psychiatry.

The following table provides details of the top ten most frequently advertised antidepressants in The Chinese Journal of Psychiatry:

Table 2: The top ten most frequently advertised antidepressants in The Chinese Journal of Psychiatry from 1996 to 2015

\begin{tabular}{|lllclll|}
\hline & Brand name & Generic name & $\begin{array}{l}\text { Number } \\
\text { of ads }\end{array}$ & $\begin{array}{l}\text { Versions } \\
\text { of ads }\end{array}$ & $\begin{array}{l}\text { Years } \\
\text { covered }\end{array}$ & Manufacturers \\
\hline 1 & Bo Le Xin & $\begin{array}{l}\text { Venlofaxine } \\
\text { Hydrochloride }\end{array}$ & 54 & 11 & $2003-2015$ & Chengdu Kanghong \\
\hline 2 & Seroxat & Paroxtine & 50 & 10 & $1996-2013$ & $\begin{array}{l}\text { Tianjin } \\
\text { SmithKline } \\
\text { French Lab }\end{array}$ \\
\& & & & & & Eli Lilly \\
\hline 3 & Cymbalta & $\begin{array}{l}\text { Duluoxetine } \\
\text { Hydrochloride }\end{array}$ & 43 & 7 & $2007-2015$ & Wyeth \\
\hline 4 & Effexor XR & $\begin{array}{l}\text { Venlofaxine } \\
\text { Hydrochloride }\end{array}$ & 34 & 10 & $2001-2010$ & N.V.Organon \\
\hline 5 & Rui Mei Long & Mirtazapine & 31 & 7 & $2008-2014$ & Xi'an Janssen \\
\hline 6 & Cipramil & $\begin{array}{l}\text { Citalopram } \\
\text { Hydrobomide }\end{array}$ & 24 & 4 & $2003-2009$ & Hunan Dongting \\
\hline 7 & $\begin{array}{l}\text { Yan Suan Liu } \\
\text { Li Da Qin }\end{array}$ & $\begin{array}{l}\text { Thioridazine } \\
\text { hydrochloride }\end{array}$ & 21 & 3 & $1996-2001$ & \\
\hline 8 & Zoloft & Sertraline & 20 & 3 & $1998-2008$ & Pfizer \\
\hline 8 & Lexpro & Escitablopram & 20 & 6 & $2007-2011$ & Xi'an Janssen \\
\hline 9 & Mi Er Ning & Mirtazapine & 18 & 4 & $2008-2015$ & Ha'erbin San Lian \\
\hline 10 & Bai Luo Te & Escitablopram & 17 & 4 & $2010-2013$ & Sichuan Kelun \\
\hline
\end{tabular}

As this table shows, there are 4 Chinese brands manufactured by Chinese companies and 3 Western brands manufactured by Chinese-Western joint ventures. The remaining 
3 are Western brands produced by Western companies. In this article, we will be making a brief comparison with UK anti-depressant drug advertising and examine the differences between British and Chinese adverts in the context of their respective prescription drug advertising policies.

\subsection{A content analysis of Chinese antidepressant advertisements}

Our content analysis is focused on all $67^{38}$ advertisements published in The Chinese Journal of Psychiatry from 1996 to 2015. To highlight the distinctive features of Chinese antidepressant advertisements, the equivalent British version is considered for comparison. A brief review of the British version shows clearly that all the adverts have very similar structure, covering almost all the categories shown in medical instructions. Therefore, only five British adverts randomly chosen from the British Journal of Psychiatry from 1996 to 2015 are included for this comparative analysis. The following table shows the average coverage percentages across all categories of information in Chinese and British adverts:

\section{Table 3: The percentage of information categories covered by Chinese and British advertisements}

\begin{tabular}{|lll|}
\hline Categories of product information & Chinese adverts & British adverts \\
\hline 1. Use & $89.55 \%$ & $100.00 \%$ \\
\hline 2. Dosage and Administration & $67.16 \%$ & $100.00 \%$ \\
\hline 3. Contraindication & $56.72 \%$ & $100.00 \%$ \\
\hline 4. Precaution & $11.94 \%$ & $100.00 \%$ \\
\hline 5. Drug interaction & $10.45 \%$ & $100.00 \%$ \\
\hline 6. Adverse effects & $37.31 \%$ & $100.00 \%$ \\
\hline 7. Overdosing & $4.48 \%$ & $40.00 \%$ \\
\hline 8. Presentation & $23.88 \%$ & $100.00 \%$ \\
\hline 9. Price information & $11.28 \%$ & $80.00 \%$ \\
\hline
\end{tabular}

One quickly sees that around 89 per cent of the advertisements in The Chinese Journal of Psychiatry include the use of antidepressants. Around two-thirds cover the dosage

\footnotetext{
38 The total number of antidepressant advertisements in The Chinese Journal of Psychiatry from 1996 to 2015 is 424, but as many advertisements for the same brand of antidepressant are repeated between 2 and 7 times in different editions of the journal, only the version that appeared for the first time is included for analysis in this section.
} 
and contraindication categories, while precaution and drug interaction are underrepresented. Meanwhile, adverse effects of antidepressants are clearly indicated in around 37 per cent of the Chinese adverts. British adverts cover all the above-mentioned six categories of information, without exceptions. Presentation is not frequently mentioned in Chinese adverts, but is consistently provided in the British ones. The overdosage category is covered by 40 per cent of the British adverts, and NHS basic price information appears in 80 per cent of the British adverts. In Chinese adverts, only around 4 per cent include information related to over-dosage and 11 per cent indicate the price of products.

Based on a manual calculation, the average number of the categories that these 67 Chinese adverts cover is 3.57. This indicates that the information Chinese antidepressants adverts provide is neither complete nor balanced (with the precaution, drug interaction and overdosage underrepresented). Furthermore, a brief look into the content of Chinese antidepressant adverts indicates that the medical information is oversimplified relative to the UK. We separated all the adverts based on different categories listed in table 3 and compared the average word count in each category in the Chinese and British adverts. The following chart shows the result:

Table 4: The average word count of each category of medical information in Chinese and British antidepressant adverts

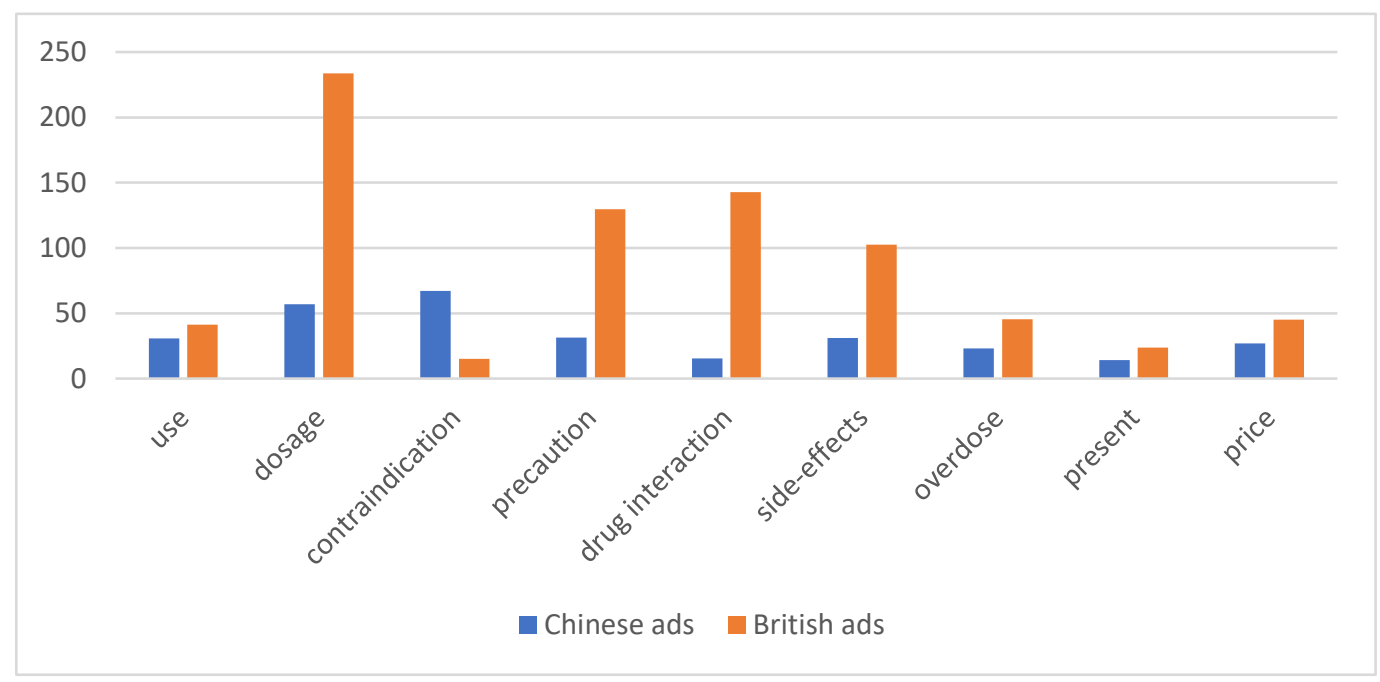


Table 4 shows that the content in relation to categories of dosage, precaution, drug interaction, adverse effects and overdose in British adverts significantly exceeds those in the Chinese. Interestingly, all of these categories focus on the use of antidepressants, and critical information concerning them, indicating the concepts of caution, danger and adverse effects. Chinese adverts clearly underrepresented such categories.

The only category in which Chinese adverts use more words than British ones is contraindication. The average word count of this category is 67 in Chinese adverts, and 15 in British ones. It will be interesting to see a comparison of representation in this category. Here, we extract two typical ones from each side:

\section{British adverts:}

1). Contra-indication: Hypersensitivity to Paroxetine. Use with MAOIs (refer to drug interactions).

2). Contra-indications: Hypersensitivity to any component of the product.

\section{Chinese adverts:}

1). Translation:

Contraindication: 1. Hyperactivity to Tianeptine or other components). 2. Children aged below 15 years. 3. Concomitant use with MAOIs. 4. Do not use Tianeptine within two weeks after MAOIs treatment. Patients who change treatment from Teaneptine to MAOIs only need to leave one day before starting MAOIs.

2). Translation:

Contraindication: Hyperactivity to Trazodone Hydrochloride. Patients with severe liver function impairment, severe Cardiac conditions, and mental disabilities should not use Tianeptine treatment.

Clearly, in British adverts, the content in the category of contraindication is predominantly represented as "hypersensitivity to any components", while in Chinese adverts, apart from the issue of hypersensitivity, general descriptions related to drug interaction and precaution are included. The word count information provided in Table 4 indicates that British adverts describe the information of these two categories in a 
much more detailed way. Therefore, it is interesting to find out here that Chinese adverts tend to mix the information related to contraindication, drug interaction and precaution together and put them all in one category of contraindication, with oversimplified language. This forms another distinctive feature of Chinese antidepressant advertising.

\subsection{A Corpus-Assisted Critical Discourse Analysis of Chinese antidepressant adverts}

To discover the predominant ways of representing antidepressants in Chinese adverts, a special corpus is built for this research including all 424 advertisements that appear in the Chinese Journal of Psychiatry from 1996 to 2015, and the size of the corpus is 73,719 words. To draw a comparison between Chinese and British texts, five British adverts have been randomly chosen, with a corpus word count of 3,842 . Three of the main corpus research methodologies: frequency analysis, collocation analysis and keyword analysis, will be used in this study.

\subsubsection{Frequency analysis: information on use and dosage}

Using a frequency analysis, from two sets of wordlists extracted from the Chinese and British antidepressant advertisements, we can see the top 20 most frequent words in the two corpora:

Table 5: Top 20 frequent words in Chinese and British antidepressants adverts

\begin{tabular}{|llll|}
\hline \multicolumn{2}{|l|}{ Chinese advertisements } & \multicolumn{2}{l|}{ British advertisements } \\
\hline 1. 焦虑 (anxiety) & 11. 法 (method) & 1. Patients & 11. Symptoms \\
\hline 2. 治疗 (treatment, treat) & 12. 用 (using) & 2. Day & 12. Caution \\
\hline 3. 抑有症 (depression) & 13. 不良 (adverse) & 3. Mg & 13. Seroquel \\
\hline 4. 抑郁 (depressive) & 14. 一 (one) & 4. Dose & 14. Anxiety \\
\hline 5. 剂量 (dosage) & 15. 患者 (patients) & 5. Treatment & 15. Daily \\
\hline 6. 对 (for) & 16. 品 (product) & 6. Disorder & 16. Vanlafaxin \\
\hline 7. 本 (this) & 17. 天 (day) & 7. Use & 17. Depressive \\
\hline 8. 片 (tablets) & 18. 次 (time) & 8. Tablets & 18. Recommended \\
\hline 9.服用 (administration) & 19. 症 (symptoms) & 9. Xl & 19. Severe \\
\hline 10. 反应 (effects) & 20. 过敏 (hypersensitivity) & 10. increased & 20. dosage \\
\hline
\end{tabular}

\footnotetext{
${ }^{39}$ In presenting the research results generated from language software, only Chinese characters and their English translations are provided. For all the Chinese characters that are incorporated in the texts, both English translations and pinyin will be provided.

${ }^{40}$ In Chinese language, 治疗 can be used as both a noun (treatment) and a verb (to treat).
} 
The top 20 words in Chinese adverts fall neatly into the following four categories of information:

1) Indication: 焦虑 (anxiety), 治疗 (treatment, treat), 抑郁症 (depression), 抑郁 (depressive), 症 (symptoms)

2) Dosage and administration: 剂量 (dosage), 片 (tablets), 服用 (administration), 法 (method), 用 (using), 一 (one), 天 (day), 次 (time)

3) Adverse effects: 不良 (adverse), 反应 (effects)

4) Contraindication: 对 (for), 本 (this), 品 (product), 过敏 (hypersensitivity), 患者 (patients)

It is interesting to find that the anxiety (jiaolv, 焦虑) is the most frequent word in the Chinese corpus, with treatment/treat (zhiliao, 治疗) as the second. Examining the texts in which anxiety occurs shows that it is uniformly used in the category of indication with rare exceptions, to describe the symptom that antidepressants can treat.

A more detailed analysis of treatment/treat (zhiliao, 治疗) in Chinese adverts shows that the following sentence is overwhelmingly used in the category of indication: (this product is used to) treat all types of depression (including mild, moderate and severe), depressive symptoms, generalized anxiety disorder. The dominant use of such a structure contributes to the high frequencies of words like anxiety (jiaolv, 焦虑), treatment/treat (zhiliao, 治疗), depression (yiyuzheng, 抑郁症), depressive (yiyu, 抑 有(3), symptoms (zheng, 症). This indicates that in Chinese adverts, the category of indication has been over-generalized into two words/phrases: anxiety, and depressive symptoms, without pointing out important differences between brands of antidepressants and the different types of depression that they treat. Thus, antidepressants have been represented as a one-for-all medicine that doctors can prescribe for patients who have depressed feeling or a generalized condition of anxiety.

By contrast, in British adverts, the description for usage of the antidepressant is much 
more clear and concise:

Use: Treatment of schizophrenia. Treatment of manic or major depressive episodes associated with bipolar disorder. Seroquel XL is effective in preventing relapse in stable schizophrenic patients who have been maintained on Seroquel XL.

Here, the use of a particular brand of antidepressant is described in relation to specific types of depression with distinctive symptomatic features, providing more detailed information for prescribing doctors.

To look into the category of dosage information, we directly searched the texts in which the most frequent words about dosage (see Table 5) occurred: dosage (jiliang, 剂量), and method (fa, 法), and using (yong, 用). Surprisingly, the short sentence “One tablet a day, convenient using method” (mei tian/ri yi pian, 每天/日一次, fu fa fang bian 服 法方便) stands out as a predominant structure and there is hardly any further information about dosage. By contrast, we find detailed information provided in the British adverts, for example:

Dosage: Adults: Depression: $20 \mathrm{mg}$ a day recommended. If necessary increase dose in $10 \mathrm{mg}$ increments to a maximum of $50 \mathrm{mg}$ according to response. Obsessive compulsive disorder: $40 \mathrm{mg}$ a day recommended. Starting dose $20 \mathrm{mg}$ a day increased weekly in $10 \mathrm{mg}$ increments. Maximum dose $60 \mathrm{mg}$ a day. Panic disorder: $40 \mathrm{mg}$ a day recommended. Starting dose $10 \mathrm{mg}$ a day; dose increased weekly in $10 \mathrm{mg}$ increments. Maximum dose $50 \mathrm{mg}$ a day. Social anxiety disorder/social phobia: $20 \mathrm{mg}$ a day recommended. Starting dose $20 \mathrm{mg}$ per day. If no improvement after at least two weeks increase by $10 \mathrm{mg}$ per week up to a maximum of $50 \mathrm{mg} /$ day according to response. Effective in 12 week placebo-controlled trials. Only limited evidence of efficacy after 12 weeks of treatment. Post-traumatic stress disorder: $20 \mathrm{mg}$ a day is recommended starting and maintenance dose. Some patients may benefit from dose increases in 10 $\mathrm{mg}$ increments as required up to a maximum of $50 \mathrm{mg} /$ day according to response. Effectiveness has not been evaluated beyond 12 weeks in placebo controlled trials.

In this typical dosage information extracted from the British corpus, we find six words (emboldened in the above text) which enter the top 20 wordlist of the British corpus shown in table 5. It provides detailed information for different types of depression, such as general depression, obsessive compulsive disorder, panic disorder, social anxiety disorder/social phobia and post-traumatic stress disorder. It also includes the instruction based on patients' response to their starting dose, such as if no improvement 
after two weeks increase by $10 \mathrm{mg}$ per week up to a maximum of $50 \mathrm{mg} /$ day. Similarly, readers are reminded of the importance of continuous treatment after recovery, and the danger of abrupt discontinuation. It is therefore fair to conclude that in this comparison of Chinese and UK antidepressant adverts, the Chinese dosage and administration information has been heavily simplified, echoing the average word count analysis shown in Table 4.

In this top 20 wordlist, we find two words 不良 (adverse), and 反应 (effects), but none of the rest of the words indicate the content of this category. Similarly, in the British wordlist, we do not find adverse effects, nor words that might be used to describe the actual side-effects of antidepressants. Therefore, the corpus research method of collocate analysis was used to investigate the features of the language describing the side-effects of antidepressants.

\subsubsection{Collocate analysis: adverse effects and contraindications}

In this section, we look at all the words that co-occur with adverse effects (buliang fanying, 不良反应) within 5 positions to the left and right. ${ }^{41}$ Wordsmith Tools (Scott, 2008) enables the generation of a list of such words collocates based on their raw frequencies, called a collocation profile. The following table shows the top ten words in this profile:

Table 6: Top collocates of 不良反应(adverse effects) in the Chinese corpus of antidepressant advertisements

\begin{tabular}{|llllll|}
\hline $\mathbf{N}$ & Word & With & Total & $\begin{array}{l}\text { Total } \\
\text { Left }\end{array}$ & $\begin{array}{l}\text { Total } \\
\text { Right }\end{array}$ \\
\hline 1 & 不良(adverse) & 不良反应 & 317 & 0 & 0 \\
\hline 2 & 反应(effects) & 不良反应 & 315 & 4 & 311 \\
\hline 3 & 较(comparatively) & 不良反应 & 59 & 27 & 32 \\
\hline 4 & 及(and) & 不良反应 & 58 & 0 & 58 \\
\hline 5 & 常见(common) & 不良反应 & 54 & 50 & 4 \\
\hline
\end{tabular}

\footnotetext{
${ }^{41}$ This decision is based on the concept of strength of relationship between a searched word and its collocates. Please refer to Wordsmith (Scott, 2008) "collocation display" for a more detailed explanation.
} 


\begin{tabular}{|llllll|}
\hline 6 & 与(with) & 不良反应 & 40 & 0 & 40 \\
\hline 7 & 包括(include) & 不良反应 & 35 & 0 & 35 \\
\hline 8 & 因此(so) & 不良反应 & 27 & 0 & 27 \\
\hline 9 & 详(detailed) & 不良反应 & 24 & 0 & 24 \\
\hline 10 & 少(rare) & 不良反应 & 24 & 4 & 20 \\
\hline
\end{tabular}

The lines in which adverse effects (buliang fanying, 不良反应) and these listed words co-occur represent the side-effects as comparatively rare. We find citations like "the common side-effects of antidepressants include very light stomach discomfort", and "for detailed information in relation to adverse effects and precautions please refer to medical instruction". The following provides six complete sentences with more contextual information:

[Translations:

1....has comparatively little influence on cytochrome oxidase, and the side-effects are comparatively rare.

2. ... is convenient to take and its dosage is easy to adjust. The toxins brought by the medicine are easy to be excreted. Besides, its side-effects are comparatively rare, and the safety range is relatively wide.

3. Adverse effects include: very light stomach discomfort and nerve disorders.

5. ... is effective for long-term treatment with low relapse rate. It is also with light sideeffects, high drug tolerance and unique package design.

6 ....causes extremely rare drug interaction, and its side-effects are rare and light.]

By contrast, British adverts adopt a universal way in displaying very clear and straightforward contents about adverse effects. Instead of looking into the collocation profile of side-effects, the following typical example provides a better picture:

SIDE-EFFECTS: Nausea, headache, insomnia, somnolence, dry mouth, dizziness, constipation, asthenia, sweating, nervousness, anorexia, dyspepsia, abdominal pain, anxiety, impotence, abnormality of accommodation, vasodilation, vomiting, tremor, paraesthesia, abnormal ejaculation/orgasm, chills, hypertension, palpitation, weight gain, agitation, decreased libido, rise in blood pressure, postural hypotension, reversible increases in liver enzymes, slight increase in serum cholesterol, hyponatraemia.

It is important to point out that the above displayed side-effects are equivalent to the 
information included in the medical instructions. Therefore, when we revisit the regulation for prescription drug advertising issued by the SAIC and SFDA: "Such contents...shall conform to the instructions approved by the food and drug administrative department of the State Council", and "The publicity may not be conducted by exaggerating or maliciously hiding certain information..." we can assume that the implementation of such regulation needs to be improved in China.

Lastly, in the category of contraindication, as the analysis in Section 3 shows, one of the distinctive features of the Chinese antidepressant adverts is that they try to mix the information related to contraindication, drug interaction and precaution under one category of contraindication and describe them in simplified terms. Therefore, we do not see any words related to drug interaction or precaution in the Chinese wordlist, and thus the significant collocates extracted for such low-frequency words are not revealing. However, when we look directly into the texts of adverts that include the content related to contraindication in Chinese adverts, we found that the following sentence is overwhelmingly used: 对本品过敏者及正在服用单胺氧化酶抑制剂的患者禁用本 品 (Not recommended in patients who have hypersensitivity to this product and patients taking MAOIs.) This explains why words for (dui, 对), this (ben, 本), product (pin, 品), hypersensitivity (guomin, 过敏), patients (huanzhe, 患者) fall within the top 20 wordlist, and this over-simplified sentence has actually been used as the only information concerning the risks (negative side) of antidepressants.

By contrast, in the British wordlist, words like patients, caution, severe, and recommended are very likely to occur in the categories of drug interaction and precaution. The word patients occurs as the most frequent word in the British corpus. Therefore, it is important to find out how British adverts construct patients, which might throw light on the content of the categories of contraindication, drug interaction and precaution. Using a Wordsmith "word cluster" function - an extended application of collocate analysis, the top ten 3 -word clusters in the British corpus can be identified: 
Table 7: The most frequent word clusters of patients in the British corpus of antidepressant Advertisements

\begin{tabular}{|lll|}
\hline Cluster & Freq. & Length \\
\hline IN PATIENTS WITH & 9 & 3 \\
\hline CAUTION IN PATIENTS & 6 & 3 \\
\hline IN PATIENTS TAKING & 4 & 3 \\
\hline HEPATICALLY-IMPAIRED PATIENTS TAKING & 3 & 3 \\
\hline WITH CAUTION IN & 3 & 3 \\
\hline USE WITH CAUTION & 3 & 3 \\
\hline IN THE ELDERLY & 2 & 3 \\
\hline INCREMENTS SOME PATIENTS & 2 & 3 \\
\hline MG INCREMENTS SOME & 2 & 3 \\
\hline MAY BENEFIT FROM & 2 & 3 \\
\hline
\end{tabular}

As we see, of these ten 3-word clusters, five contain patients, with the first one as in patients with, and the second caution in patients. Another two frequent clusters containing caution are with caution in and use with caution. It is fair to assume that the frame use with caution in patients with/taking should form a repeated pattern. Therefore, all the lines that containing in patients were extracted, to ascertain whether this assumption is right.

\section{Table 8: Concordance lines of in patients in the British Corpus of Antidepressant Adverts}

N Concordance

20 in particular serotonergic drugs, lithium, clozapine or haloperidol in patients taking warfarin. Potent CYP3A4 inhibitors or drug combinations

21 to an effective dose. Efficacy and satety have not been evaluated in patients over 65 years with depressive episodes in the framework of

22 drugs known to prolong the QTC interval, especially in the elderly, in patients with congenital long QT syndrome, congestive heart failure,

23 disorder: A maximum of two weeks supply should be considered in patients with increased risk factors for suicide at initiation of treatment,

24 caution in elderly or hepatically-impaired patients taking cimedidine, in patients taking other CNS-active drugs in particular serotonergic drugs,

25 . Precautions History of mania. Cardiac conditions: caution. Caution in patients with epilepsy; stop treatment if seizures develop. Driving and

26 CYP3A4 such as azole antifungals and macrolide antibiotics. Caution in patients with a family history of QT prolongation, and in combination

27 , patients aged below 18 years. PRECAUTIONS: Use with caution in patients with myocardial infarction, unstable heart disease, renal or

28 or if they become or intend to become pregnant. Use with caution in patients taking other CNS-active drugs or in the elderly or

29 with quetiaaine as compared to those treated with placebo. Caution in patients with cardiovascular disease, cerebrovascular disease or other

30 of aggression and psychomotor restlessness. Use with caution in patients with established cardiac disease that may increase the risk of

31 . Appropriate clinical monitoring is advisable in diabetic patients and in patients with risk factors for the development of diabetes mellitus. 
As predicted, we find 6 lines containing caution in patients with/taking. And it is obvious to see that the majority of these lines are used to refer to the precaution and drug interaction categories (with lines about in patients with for precaution, and in patients taking for drug interaction), with a small portion of the content being used in the category of dosage information (line 23). This content provides detailed information concerning patients' medical conditions, such as patients with congenital long DT syndrome, epilepsy, myocardial infarction, or established cardiac disease. The concept of caution is continuously emphasised, keeping readers alert. This content is equivalent to that provided in the medical instructions accompanying antidepressants. By contrast, Chinese adverts remain silent in such areas. This echoes our analyses shown in Table 5, that only around 12 per cent of adverts include information related to precaution, around 10.4 per cent to drug interaction, and the contents in these two categories are usually over-simplified.

Overall, the differences between Chinese and British adverts are significant. Firstly, most Chinese adverts cover the categories of information related to the use, dosage, side-effects and contraindications of antidepressants. British adverts, on the other hand, not only cover the above-mentioned categories, but use more space for the categories of precaution and drug interaction. Secondly, the content of every category in Chinese adverts is generally oversimplified, for example, with the use of antidepressants described as to treat depressive symptoms and anxiety, with the dosage information as once a day, with side-effects as very rare (light), and with contraindication as hypersensitivity to this product. British adverts, by contrast, provide a significantly more detailed picture for each category, especially in the dosage information. Lastly, British adverts have highlighted the concept of caution by providing large-scale detailed information in relation to precaution and drug interaction while Chinese adverts keep silent in this issue.

\subsubsection{Keyword analysis: changes over time}


Using Wordsmith keyword analysis one can see even more clearly which aspects of antidepressants have been focused on, and which ones less talked about over time. As the British adverts have adopted a consistent way (in both structure and content) of displaying antidepressant information, we will mainly look at what categories of information Chinese adverts have emphasized from 1996 to 2015, and have they changed over time?

Based on the analysis of the frequency changes of Chinese adverts and their related social contexts shown in Table 1, we divide the Chinese corpus into three time Phases: 1996 to 2002, 2003 to 2008 and 2009 to 2015 . The following table shows the three sets of keyword lists for the defined Phases; (the words given bold indicate the distinctiveness of each time Phase):

Table 9: Distribution of keywords in the Chinese corpus of antidepressant adverts

\begin{tabular}{|lll|}
\hline Phase 1 (1996 to 2002) & Phase 2 (2003 to 2008) & Phase 3 (2009 to 2015) \\
\hline 治疗(treatment) & 服用(use) & 焦虑 (anxiety) \\
抑郁症 (depression) & 焦虑(anxiety) & 抑郁症 (depression) \\
焦虑(anxiety) & 治疗 (treatment) & 抑郁 (depressive) \\
剂量(dosage) & 抑郁症 (depression) & 剂量 (dosage) \\
服用(use) & 抑郁 (depressive) & 治疗 (treatment) \\
郁乐复 (Zoloft) & 剂量(dosage) & 品 (product) \\
药 (medication) & 不良(adverse) & 患者 (patients) \\
抑郁 (depressive) & 制剂 (inhibitor) & 不良(adverse) \\
盐酸 (hydrochloric acid) & 抑 (inhibitor) & 适应症 (indication) \\
服药(taking medication) & 药物 (medication) & 过敏 (hypersensitivity) \\
症(symptoms) & 氧化酶 (oxidase) & 说明书 (medical instruction) \\
疗效 (effectiveness) & 反应 (effects) & 反应 (effects) \\
您 (you) & 诺思(Efextor XR) & 详 (detailed) \\
强迫症(compulsive disorder) & 每日(per day) & 禁用 (contraindication) \\
病人(patients) & 怡 (Efextor XR) & 胺 (amine) \\
症状(symptoms) & 药 (medication) & 氧化酶 (oxidase) \\
服(taking) & 适应症 (indication) & 盐酸 (hydrochloric acid) \\
副作用(side-effects) & 胺 (an, amine) & 汀(Fluoxe[tine]) \\
有效 (effective) & 症 (symptoms) & 症状 (symptoms) \\
\hline
\end{tabular}

These three keyword lists overlap each other to a large extent, including a certain amount of common words such as treatment/treat, depression, anxiety, dosage, etc., 
words indicating the chemical or brand names of antidepressants, such as Efextor XR (yinuosi, 怡诺思) and Zoloft (yulefu, 郁乐复), some distinctive phasal key words stand out, carrying important connotations relating to the development of Chinese antidepressant advertisements. For example, in the first Phase, two phasal key words are: effectiveness and effective, implying that from around the mid-1990s to the beginning of the $2000 \mathrm{~s}$, the basic theme of Chinese adverts is that antidepressants are effective in treating depressive symptoms, and such effectiveness is repeatedly emphasised. From the second Phase onwards, more formal and scientific names of the categories of information start to appear, such as indication (shiyingzheng, 适应症), and adverse effects, implying that Chinese adverts began to develop in a more scientific and objective way. In a similar way, in the third Phase, contraindication (jinyong, 禁 用) and hypersensitivity entered as new key words, indicating that Chinese adverts in the last ten years have begun to include information related to the contraindications of antidepressants, though these are oversimplified as "Not recommended for patients who have hypersensitivity to any components of the product". At the same time, we found words detailed (xiang, 详), and medical instruction (shuomingshu, 说明书) enter this key word list, and an examination of these two words in the context of Chinese adverts indicates that they occur in the typical sentence: "For detailed information related to contraindication and adverse effects of this product, please refer to the medical instructions." This implies that drug advertising regulations have been tightened to require the inclusion of the categories of contraindications and adverse effects, but the pharmaceutical companies have responded to this simply by adding a standard clause referring the reader to the medical instructions.

\section{Conclusion and Discussion}

On a linguistic level, Chinese adverts tend to use generic language to represent antidepressants as very effective, with rare side-effects, and as a convenient-to-use medication. In describing the use of antidepressants, they over-emphasize the symptomatic problems that antidepressants can treat, especially anxiety, and 
depressiveness, catering to the localization and conceptualization of mental illness and antidepressants within Chinese culture. That is, Chinese people tend to somatize depression $^{42}$ due to the social stigma attached to psychological or psychiatric conditions. The adverse effects of antidepressants have been largely represented in highly generic language such as very rare and extremely light. This leads to the unbalanced representation of the information in Chinese medical journals. The basic theme of caution, which is continuously reiterated in British adverts, does not exist in Chinese adverts, because the information related to the categories of drug interaction and precaution is largely omitted. Being exposed to such limited, inaccurate and unbalanced sources of information about antidepressants may lead doctors to inaccurately or overprescribe antidepressants.

The findings of the discourse analysis of Chinese antidepressant advertisements reflect that, from the policy level, more nuanced Chinese regulatory laws related to the contents of prescription drug advertising need to be established. As addressed earlier, the current regulation related to the content of advertisements states that they shall conform to the instructions approved by the food and drug administrative department of the State Council. A recent development here is that in 2015, China's Advertising Law saw its first amendment in two decades highlighting that: Drug and device advertisements must clearly state critical information about the products, such as contraindication and adverse effects; Drug and device advertisements must not contain absolute assurances or guarantees of the product's safety ${ }^{43}$. This indicates that China has realized the necessity of including critical information in the advertisements. However, as our diachronic analysis of the keywords shows, pharmaceutical companies tend to use the sentence: Please refer to the medical instructions for detailed information related to adverse effects and contraindication. Therefore, to ensure that detailed and balanced information is provided, regulatory laws should further indicate that all the categories of information displayed in the instructions should be covered,

\footnotetext{
42 Kleinman 1982.

${ }^{43}$ Standing Committee of the NPC and SAIC 2015, article 16.
} 
and the content in each category should reach a certain specified threshold of detail.

In policy terms, to ensure the accessibility, reliability and balanced supply of information in medical advertisements, advertising law also needs to be effectively implemented and enforced. This clearly depends on a complex mix of coordinated action between many interest and stakeholder groups: government, regulatory authorities, medical organizations, pharmaceutical companies, media, public health service and others. Moreover, due to the large financial stakes involved and the complex financial and political relationships between these groups enforcing these laws can be very difficult. Complicating this, as our discourse analysis shows, Chinese advertisements describe the use of antidepressants as treating an inappropriately wide range of symptomatic problems, minimizing their side-effects. These problems are closely related to the cultural understanding of mental depression and antidepressants in China. Recognizing this, it is important to draw some of the conclusions in regards to debates around policy learning and transfer. In the area of antidepressant drug advertising, Chinese policy-makers must remember that:

- They cannot simply copy an existing policy structure from another area/country and expect it to work in the same way. As our analysis demonstrates, there are too many interdependent factors for this to occur.

- Policies always have social and cultural meanings. Mental health is one of the most socially and culturally difficult areas for societies to confront. Hence, this will continue to be a highly contested policy area.

- Nevertheless, learning from other policy actors and contexts can be very useful. The limited two country comparison (China-UK) that was utilized in this article highlighted a number of weaknesses in the Chinese regulatory framework. This does not imply that copying UK regulation would necessarily solve Chinese policy issues. However, as a method of reflecting upon internal structures and strategies, sensitive and contextual international policy comparison is an excellent choice.

- Lastly, this is a continual policy process. Medications, information technologies 
and advertising do not stand still. Though Chinese antidepressant policy could be seen to be 'catching up' with British regulation, this does not mean that it ends there. 


\section{References:}

ABPI (Association of British Pharmaceutical Industry). 2016. Code of Practice for the Pharmaceutical Industry 2016. [Online]. Available from:

https://www.abpi.org.uk/media/1605/code_of_practice_2016.pdf. [Accessed 19 July 2018].

Ansell, Chris and Robert Geyer. 2017. "Pragmatic Complexity: A New Foundation for Moving Beyond Evidence Based Policy Making.” Policy Studies 38(2): 149-167.

Bai, Yuping. 2015. "Case Studies of the Approval of Food \& Drug Advertisements", Baidu Wenku, July, 2015,

http://wenku.baidu.com/view/4e579888650e52ea551898a8.html. Accessed 20 July 2016.

Baum, E.L., 2013. Spit, Chains, and Hospital Beds: A History of Madness in Republican Beijing, 1912-1938. University of California, San Diego.

Benson, David and Andrew Jordan. 2011. "What Have We Learned From Policy Transfer Research: Dolowitz and Marsh Revisited." Political Studies Review 9(3): 36678.

Byrne, David, and Gillian Callaghan. 2013. Complexity Theory and the Social Sciences: The State of the Art. Abingdon: Routledge.

Cairney, Paul. 2015. The Politics of Evidence-Based Policy Making. London: Palgrave.

Cameron, Lynne, and Diane Larsen-Freeman. 2007. "Complex systems and applied linguistics." International Journal of Applied Linguistics 17(2): 226-240.

Cohen, David., Michael McCubbin, Johanne Collin and Guilhème Pérodeau. 2001. "Medications as Social Phenomena." Health 5(4), 441-469.

Coveney, Peter, and Roger Highfield. 1995. Frontiers of Chaos: The Search for Order in a Chaotic World. New York: Fawcett Columbine.

Dolowitz, David and David Marsh. 2000. "Learning from Abroad: The Role of Policy Transfer in Contemporary Policy Making." Governance 13(1), 5-24.

Easterly, William. 2006. The White Man's Burden: Why the West's Efforts to Aid the Rest Have Done So Much Ill and So Little Good. New York: Penguin.

Fairclough, Norman. 2013. "Critical Discourse Analysis and Critical Policy 
Studies." Critical Policy Studies 7(2), 177-197.

Fairclough, Norman. 2001. "The Discourse of New Labour: Critical Discourse Analysis." In Margaret Wetherall, Stephanie Taylor and Simeon Yates (eds.), Discourse as Data: A Guide for Analysis. London: Sage Publications and the Open University, 229-266.

Falk, Ian. 1994. "The Making of Policy: Media Discourse Conversations." Discourse 15(2), 1-12.

George, Susan. 1994. A Fate Worse Than Debt. London: Penguin.

Geyer, Robert. 2011. "The Politics of EU Health Policy and the Case of Direct-toConsumer Advertising for Prescription Drugs." The British Journal of Politics and International Relations 13(4), 586-602.

Geyer, Robert. 2012. "Can complexity move UK policy beyond 'evidence-based policy making' and the 'audit culture? Applying a 'complexity cascade' to education and health policy." Political Studies 60(1): 20-43.

Geyer, Robert, and Paul Cairney. (eds.). 2015. Handbook on Complexity and Public Policy. Cheltenham UK: Edward Elgar Publishing.

Geyer, Robert, and Samir Rihani. 2010. Complexity and Public Policy: A New Approach to Twenty-First Century Politics, Policy and Society. Abingdon: Routledge.

Glinert, Lewis H. 2005. "TV Commercials for Prescription Drugs: A Discourse Analytic Perspective." Research in Social and Administrative Pharmacy 1(2), 158-184.

Green, A. Richard, Peter M. Haddad, and Jeffrey K. Aronson. 2018. "Marketing medicines: charting the rise of modern therapeutics through a systematic review of adverts in UK medical journals (1950-1980)." British journal of clinical pharmacology.

Hamilton, Myra. 2014. "The 'New Social Contract' and the Individualisation of Risk in Policy." Journal of Risk Research 17(4), 453-467.

Ng, Siu-man, Cecilia LW Chan, David YF Ho, Yu-Yeuk Wong, and Rainbow TH Ho. 2006, "Stagnation as a distinct clinical syndrome: comparing 'Yu'(stagnation) in traditional Chinese medicine with depression." British Journal of Social Work 36 (3): 467-484.

House of Commons. 2005. The Influence of the Pharmaceutical Industry: Fourth Report of Session 2004-05. London: The Stationary Office. 
Jacobs, Keith. 2006. "Discourse Analysis and its Utility for Urban Policy Research." Urban Policy and Research 24(1), 39-52.

Jin, Zhe. 2016. "Treatment Rate under 10\%, Imported Antidepressants still prevail in China”, Daily Economist News, September, 2016, http://www.nbd.com.cn/articles/2016-09-21/1040051.html. Accessed 12 Feb 2018.

Jones, Miren, Sheila M. Greenfield, and Collin P. Bradley. 1999. "A Survey of the Advertising of Nine New Drugs in the General Practice Literature." Journal of clinical pharmacy and therapeutics 24(6), 451-460.

Kleinman, Arthur. 1982. "Neurasthenia and depression: a study of somatization and culture in China." Culture, medicine and psychiatry 6(2), 117-190.

Kleinman, Arthur. 1992. "Culture and somatic experience: The social course of illness in neurasthenia and Chronic Fatigue Syndrome." Psychosomatic Medicine, 54, 546560.

Larsen-Freeman, Diane. 1997. "Chaos/Complexity Science and Second Language Acquisition." Applied Linguistics 18(2), 141-165.

Larsen-Freeman, Diane, and Cameron Lynne. 2008. Complex Systems and Applied Linguistics. Oxford: Oxford University Press.

Lee, Philip R., Peter Lurie, Milton M. Silverman, and Mia Lydecker. 1991. Drug promotion and labeling in developing countries: an update." Journal of clinical epidemiology 45: 49-55.

Lexchin, Joel. 2009. Analysing pharmaceutical advertisements in medical journals. Understanding and Responding to Pharmaceutical Promotion, 41-56.

Lin, Keh-Ming. 1980. Traditional Chinese medical beliefs and their relevance for mental illness and psychiatry. In Arthur. Kleinman \& T. Y. Lin (Eds.), Normal and abnormal behavior in Chinese culture. Dordrecht, The Netherlands: D. Reidel, 95-111.

Lövdahl, Ulrica, Åsa Riska and Elianne Riska. 1999. "Gender display in Scandinavian and American Advertising for Antidepressants." Scandinavian Journal of Public Health 27(4), 306-310.

Luke, Allan. 1997. "New Narratives of Human Capital: Recent Redirections in Australian Educational Policy." The Australian Educational Researcher 24(2), 1-21. 
Ma, Feng and Nan Lou. 2014. "Regulation of Drug Promotion in China", Covington \& Burling LLP, May/June, 2013, https://www.cov.com/ /media/files/corporate/publications/2013/05/regulation_of_dru g_promotion.pdf. Accessed 17 July 2016.

Mainzer, Klaus. 1997. "Symmetry and Complexity: Fundamental Concepts of Research in Chemistry." Hyle 3, 29-49.

Marston, Greg. 2000. "Metaphor, Morality and Myth: A Critical Discourse Analysis of Public Housing Policy in Queensland." Critical Social Policy 20(3), 349-373.

PMCPA. 2018. Prescription Medicines Code of Practice Authority. [Online]. Available from: http://www.pmcpa.org.uk/Pages/default.aspx. [Accessed 19 July 2010]

Rihani, Samir. 2002. Complex Systems Theory and Development Practice. London: Zed Books.

Scott, Mike. 2008. WordSmith Tools Version 5.0. Liverpool: Lexical Analysis Software.

Sealey, Alison, and Bob Carter. 2004. Applied linguistics as social science. A\&C Black.

Shi, Qiang, and Peixue, Ling. 2007. "The problems in the Essential Drugs List in China and proposed solutions." Food and Drug 8(12A), 55-59.

Standing Committee of the NPC (National People's Congress) and SAIC (State Administration for Industry \& Commerce). 2015. Advertising Law of the People's Republic of China.

Stryer, Daniel, and Lisa A. Bero. 1996. "Characteristics of Materials Distributed by Drug Companies." Journal of General Internal Medicine 11(10), 575-583.

Wang, Fang. 2013. A social constructionist analysis of the discourse of mental depression in British and Chinese news: a corpus-based study (Doctoral dissertation, University of Birmingham).

World Health Organisation. 1988. Ethical criteria for medicinal drug promotion. Geneva.

Zhan, Mei. 2011. "Human Oriented? Angels and Monsters in China's Health-Care Reform." East Asian Science, Technology and Society 5(3), 291-311. 